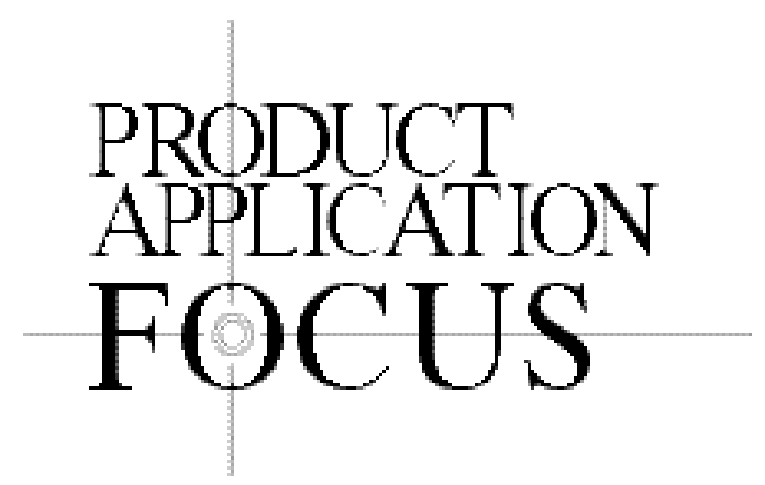

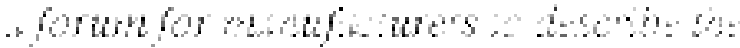

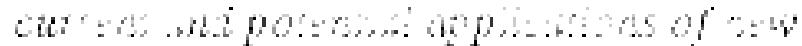

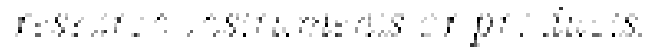

\title{
Small-Sample Total RNA Purification: Laser Capture Microdissection and Cultured Cell Applications
}

\author{
Karen E. Dolter and Jeffrey C. Braman \\ Stratagene, La Jolla, CA, USA
}

BioTechniques 30:1358-1361 (June 2001)

\begin{abstract}
Gene expression studies require analysis of RNA, but isolation of total RNA from very small samples by traditional methods can be difficult and inefficient. The Absolutely RNA ${ }^{\mathrm{TM}}$ microprep kit provides a convenient method for isolating total RNA from small num bers of cells such as those harvested by laser capture microdissection (LCM). The protocol includes binding of RNA to a solid support, thus eliminating the need for organic extraction and alcohol precipitation. DNase digestion on the solid support reduces or eliminates DNA contamination and minimizes RNA handling. Efficient washing removes contaminants, and elution in a small volume of buffer results in high-purity RNA at a concentration appropriate for demanding applications such as RT-PCR. RNA isolated from as few as 200 laser capture microdissected brain tumor cells resulted in detection of low, medium, and highly expressed genes by conventional and real-time $R T$ - $P C R$.
\end{abstract}

\section{INTRODUCTION}

There is significant interest in analyzing gene expression from distinct cell populations. Heterogeneous populations of cells within tissues of various types possess correspondingly different patterns of gene expression, and these cells must be separated from one another for accurate assessment of gene expression. Laser capture microdissection (LCM) is a particularly useful tool for recovering small cell samples and even enables researchers to collect individual cells from tissue sections (4). This method facilitates the separation of histologically different cells so that proteins, DNA, or RNA from these cells can be analyzed in isolation from the surrounding unwanted cells. In addition to LCM samples, some samples of cells in culture are available in limiting amounts, such as slow-growing clones or primary cells with a limited life span. Isolation of RNA from small cell samples can be challenging because of the inefficiency of protocols designed for larger samples. For example, yields can be low because of losses during phenol-chloroform extraction and/or ethanol precipitation. We have developed a method specifically for the purpose of isolating total RNA from small samples of cells. The protocol was designed for applications such as LCM, where samples of 100-1000 cells are common, but has been successfully applied from 1 cell up to $5 \times 10^{5}$ cells. The resulting RNA is of high quality and is ideal for demanding quantitative and conventional RT-PCR applications.

\section{MATERIALS AND METHODS}

All materials were supplied by Stratagene (La Jolla, CA, USA) unless indicated otherwise. 


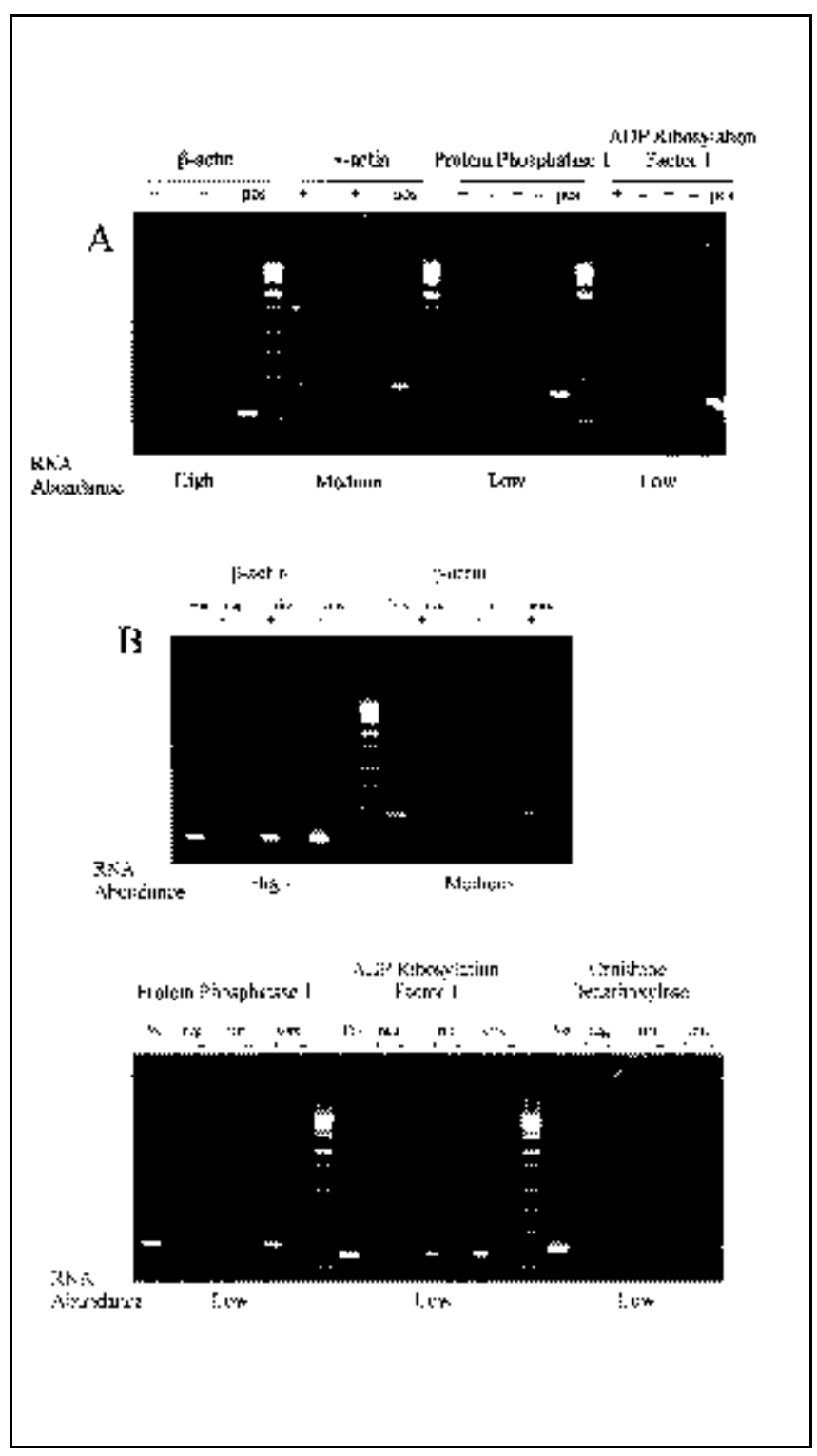

Figure 1. RT-PCR analysis of RNA isolated from human brain tumor LCM samples. LCM was used to harvest 200 cells from the core (A) and 1000 cells from the rim and core (B) of a brain tumor section. (A) Half of the RNA from 200 cells was used for cDNA synthesis. One-twentieth of the cDNA was used for PCR amplification of $\beta$-actin, one-fifth of the cDNA was used for $\gamma$-actin, and one-fourth of the cDNA was used for low-abundance RNAs (protein phosphatase 1 and ADP ribosylation factor 1). RT-PCR was performed using Stratagene's Primer Sets for RT-PCR allowing amplification of human genes of varying abundance levels. Taq2000 DNA polymerase was used for the PCR in a RoboCycler 96 temperature cycler according to the instructions provided with the primers and as described in the Materials and Methods section. Half of each PCR product was electrophoresed in a $1.5 \%$ agarose gel, equivalent to the RNA from 2.5 cells ( $\beta$-actin), 10 cells ( $\gamma$-actin), and 13 cells (protein phosphatase 1 and ADP ribosylation factor 1). (B) Eight microliters of each $30-\mu \mathrm{L}$ sample from 1000 cells were used for cDNA synthesis. One-tenth of the cDNA was used for detecting high- and mediumabundance RNA ( $\beta$-actin and $\gamma$-actin), and one-fifth of the cDNA was used for detecting low-abundance RNAs (protein phosphatase 1, ADP ribosylation factor 1, and ornithine decarboxylase). Two-fifths of each PCR were electrophoresed on a $1.5 \%$ agarose gel. This is equivalent to 11 cells for the highand medium-abundance RNAs and 21 cells each for the low-abundance RNAs. "Pos" in panels A and B represents a positive PCR control for each primer set using template provided with Stratagene's Primer Sets for RTPCR. The designations (+) and (-) in panels A and B refer to the presence or absence of MMLV-RT in the RT-PCR for each primer set. PCR products present in the (-) lanes results from DNA contamination in the RNA sample. "Neg" in panel B refers to NTC reactions for each primer set, with (+) and without (-) MMLV-RT.

\section{Laser Capture Microdissection}

LCM was performed using CapSure ${ }^{\mathrm{TM}}$ transfer film with the PixCell II ${ }^{\circledR}$ LCM system (Arcturus Engineering, Mountain View, CA, USA). Cells were harvested from the invasive rim and the core of a frozen human brain tumor section (M. Berens, Barrow Neurological Institute, Phoenix, AZ, USA).

\section{RNA Isolation}

Total RNA was isolated using the Absolutely RNA ${ }^{\mathrm{TM}}$ microprep kit. Cells are disrupted in $100 \mu \mathrm{L}$ of a lysis buffer containing guanidine thiocyanate, a strong protein denaturant, and $0.7 \mu \mathrm{L} \beta$-mercaptoethanol. Each sample is then mixed with an equal volume of $70 \%$ ethanol and applied to a spin cup where the RNA binds to a silica-based fiber matrix. After centrifugation and disposal of the flow-through, the fiber matrix is washed with $600 \mu \mathrm{L}$ low-salt wash buffer and then dried with a 2-min centrifugation. DNase treatment is performed using $50 \mathrm{U}$ DNase with $25 \mu \mathrm{L}$ DNase digestion buffer in a 15 -min incubation at $37^{\circ} \mathrm{C}$ to remove contaminating DNA. The fiber matrix is washed with $500 \mu \mathrm{L}$ high-salt wash, followed by 600 and $300 \mu \mathrm{L}$ low-salt wash to remove DNase and other contaminants. The spin cup is centrifuged at $13000 \times g$ for $2 \mathrm{~min}$ to dry the fiber matrix. Highly pure RNA is eluted from the fiber matrix with $30 \mu \mathrm{L}$ elution buffer $(10$ $\mathrm{mM}$ Tris, $\mathrm{pH}$ 7.5) (http://www.stratagene.com/manuals/ 400752.pdf).

\section{Conventional RT-PCR}

The ProSTAR ${ }^{\mathrm{TM}}$ first-strand RT-PCR kit was used for cDNA synthesis (http://www.stratagene.com/pcr/table/rtpcr.htm). Each RNA sample was incubated with 60 ng random primers in a total volume of $16.4 \mu \mathrm{L}$ at $65^{\circ} \mathrm{C}$ for $5 \mathrm{~min}$, followed by slow cooling at room temperature $(10 \mathrm{~min})$ to allow the primers to anneal to the RNA. The remaining reaction components were then added to a final volume of $20 \mu \mathrm{L}$ containing $1 \times$ first-strand buffer, $16 \mathrm{U}$ RNase Block Ribonuclease Inhibitor, $1 \mathrm{mM}$ each $\mathrm{dNTP}$, and $20 \mathrm{U}$ Moloney murine leukemia virus reverse transcriptase (MMLV-RT), and the reaction was incubated at $37^{\circ} \mathrm{C}$ for $1 \mathrm{~h}$. The reverse transcriptase was then inactivated by incubation at $90^{\circ} \mathrm{C}$ for $5 \mathrm{~min}$. PCR was performed using Stratagene's Primer Sets for RTPCR for genes of varying abundance levels (human) (http://www.stratagene.com/oligo/primer_probes.htm) using Taq2000 ${ }^{\mathrm{TM}}$ DNA polymerase in a RoboCycler ${ }^{\circledR} 96$ temperature cycler (http://www.stratagene.com/instruments/robocycler.htm) according to the instructions provided with the primers. Each PCR contained $1 \times$ Taq DNA polymerase buffer, $200 \mu \mathrm{M}$ each dNTP, 25 pmol each primer, and $2.5 \mathrm{U}$ Taq2000 DNA polymerase. The reactions were run at $94^{\circ} \mathrm{C}$ for $2 \mathrm{~min}$, followed by 35 cycles of $94^{\circ} \mathrm{C}$ for $1 \mathrm{~min}, 60^{\circ} \mathrm{C}$ for $1 \mathrm{~min}$, and $72^{\circ} \mathrm{C}$ for $1.5 \mathrm{~min}$, followed by $10 \mathrm{~min}$ at $72^{\circ} \mathrm{C}$. The samples were electrophoresed in $1.5 \%$ agarose gels.

\section{Real-Time RT-PCR}

RT-PCR analysis of total RNA was performed using the single-tube quantitative RT-PCR core reagent kit and the molecular beacon human glyceraldehydes-3-phosphate dehydrogenase (GAPDH) expression analysis kit (http://www.stratagene.com/q_pcr/index.htm). Each $50-\mu \mathrm{L}$ reaction contained 3 
$\mu \mathrm{L}$ RNA, $5 \mu \mathrm{L} 10 \times$ core RT-PCR buffer, $3.5 \mu \mathrm{L} 50 \mathrm{mM}$ $\mathrm{MgCl}_{2}, 2 \mu \mathrm{L}$ human GAPDH primer mixture (30 pmol), $1 \mu \mathrm{L}$ human GAPDH molecular beacon (25 pmol), $2 \mu \mathrm{L} 20 \mathrm{mM}$ dNTP mixture, 1.25 U StrataScript ${ }^{\mathrm{TM}}$ RT, $0.5 \mu \mathrm{L}$ Taq2000 DNA polymerase $(2.5 \mathrm{U})$, and $300 \mathrm{mM}$ final concentration of reference dye. The reactions were run in the ABI 7700 realtime thermal cycler (Applied Biosystems, Foster City, CA, USA) for $30 \mathrm{~min}$ at $45^{\circ} \mathrm{C}, 3 \mathrm{~min}$ at $95^{\circ} \mathrm{C}$, and 40 cycles of $30 \mathrm{~s}$ at $95^{\circ} \mathrm{C}, 1 \mathrm{~min}$ at $55^{\circ} \mathrm{C}$, and $30 \mathrm{~s}$ at $72^{\circ} \mathrm{C}$.

\section{Electrophoresis}

Total RNA (200 ng) was electrophoresed in a $1.2 \%$ formaldehyde-agarose gel in a Joule Box ${ }^{\mathrm{TM}}$ electrophoresis apparatus (http://www.stratagene.com/instruments/joule_ box.htm). The gel contained $1.2 \%$ agarose, $1 \times$ MOPS buffer (20 mM MOPS/8 mM sodium acetate/1 mM EDTA), $0.33 \mathrm{M}$ formaldehyde. The RNA samples were mixed with $9 \mu \mathrm{L}$ loading buffer $[1 \times$ MOPS buffer, $50 \%$ formamide, $2.2 \mathrm{M}$ formaldehyde, $10 \times$ loading dye (50\% glycerol, $1 \mathrm{mM}$ EDTA, $0.05 \%$ bromophenol blue, $0.05 \%$ xylene cyanol FF), 20 $\mu \mathrm{g} / \mathrm{mL}$ ethidium bromide], incubated at $60^{\circ} \mathrm{C}$ for $10-15 \mathrm{~min}$ and placed on ice before loading in the gel. Images of the gel were generated with the Eagle Eye ${ }^{\circledR}$ II still video system (http://www.stratagene.com/instruments/eagle_eye.htm).

\section{RESULTS}

\section{Analysis of LCM Samples}

Determination of gene expression patterns responsible for the invasiveness of a tumor is important for understanding tumor cell biology and development of cancer treatments. Com

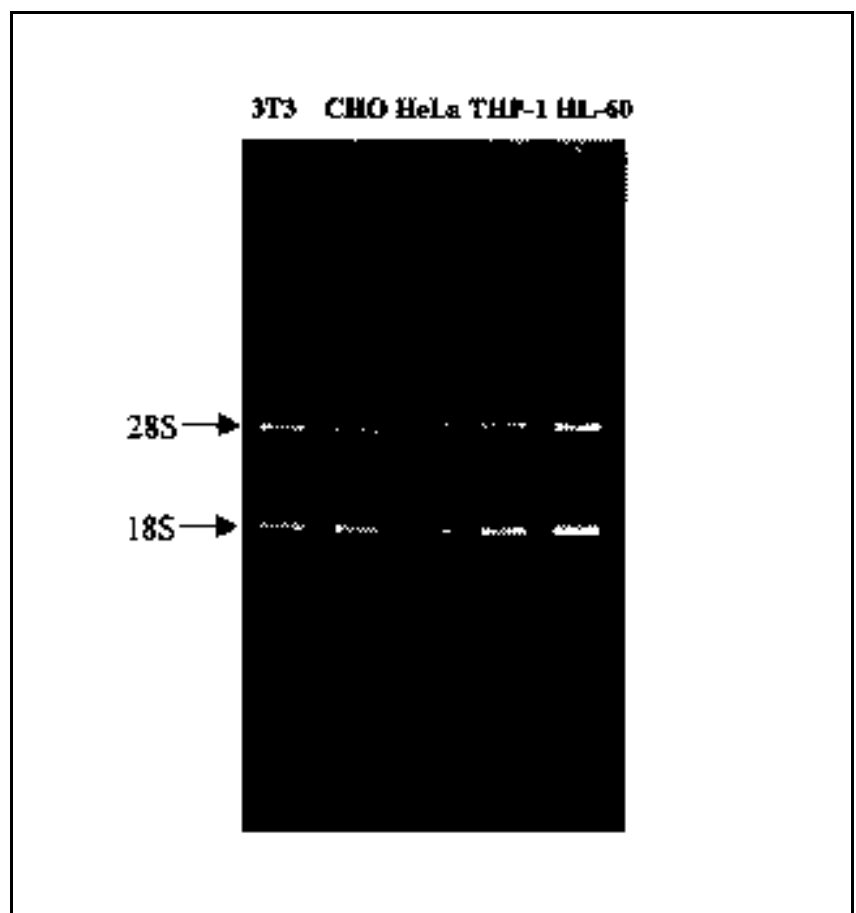

Figure 2. Formaldehyde-agarose gel electrophoresis of total RNA from different cell lines. RNA $(200 \mathrm{ng})$ isolated from $5 \times 10^{5}$ cells was run in the gel in the presence of ethidium bromide and imaged using an Eagle Eye II still video system. parison of gene expression in cells from the core relative to the invasive rim of a tumor can provide insight into genes im portant for tumor invasiveness. In a trial experiment to test the effectiveness of the Absolutely RNA method for small cell number samples, total RNA was isolated from LCM samples from the invasive rim and the noninvasive core of a human brain tumor section using the Absolutely RNA microprep kit. RNA of different abundance levels (1) was detected from samples of 200 and 1000 cells (Figure 1). For the 200-cell sample, high-abundance RNA ( $\beta$-actin) was detected from a portion of the RT-PCR product equivalent to 2.5 cells, medium-abundance RNA ( $\gamma$-actin) from a portion equivalent to 10 cells, and low-abundance RNA (protein phosphatase 1 and ADP ribosylation factor 1) from portions equivalent to 13 cells (Figure 1A). For the 1000-cell samples (Figure 1B), high- and medium-abundance RNA was detected from portions of the RT-PCR products equivalent to 11 cells, and lowabundance RNA (protein phosphatase 1, ADP ribosylation factor 1, and ornithine decarboxylase) was detected from portions equivalent to 21 cells. A comparison of cells from the invasive rim and the core of the brain tumor showed expression of these genes in both cell types (Figure 1B).

\section{RNA from Tissue Culture Cells}

RNA was isolated from $5 \times 10^{5}$ cells using the Absolutely RNA microprep kit and electrophoresed in a formaldehydeagarose gel to check the integrity of the RNA. Cultured cell lines included human HeLa, THP-1 and HL-60 cells, mouse $\mathrm{NIH} / 3 \mathrm{~T} 3$ cells, and hamster $\mathrm{CHO}$ cells. All of the samples were intact, as observed by the distinct $28 \mathrm{~S}$ and $18 \mathrm{~S}$ ribosomal RNA bands (Figure 2).

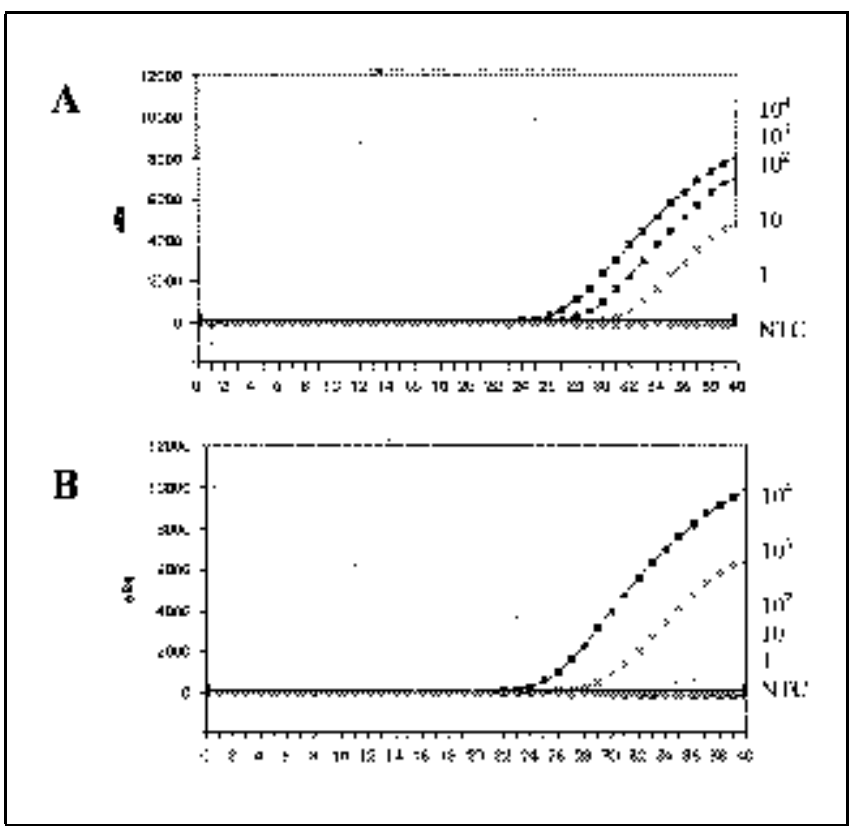

Figure 3. Real-time RT-PCR analysis of total RNA isolated from HeLa and THP-1 cells. One-tenth of the total RNA isolated from the equivalent of $10^{4}, 10^{3}, 10^{2}, 10$, and 1 (A) HeLa and (B) THP- 1 cells was used with the single-tube quantitative RT-PCR core reagent kit and the molecular beacon human GAPDH expression analysis kit. Aliquots equivalent to each cell num ber were taken from dilutions of cell lysates. $\Delta \mathrm{Rn}$, total fluorescence; NTC, no template control. 


\section{Detection of RNA Using Real-Time RT-PCR}

Quantitative, real-time RT-PCR is a powerful application for RNA analysis. In addition to high sensitivity, this method provides a means for comparing the quantity of a specific RNA sequence in different samples to each other and/or to a standard curve for absolute quantification. RNA from varying numbers of cultured HeLa and THP-1 cells was isolated using the Absolutely RNA microprep kit and subjected to realtime RT-PCR analysis by the molecular beacon method (8) using a fluorogenic probe (beacon) specific for human GAPDH. The beacon fluoresces where it hybridizes to the target sequence. The threshold cycle number $\left(\mathrm{C}_{t}\right)$ at which a fluorescence signal becomes detected is inversely proportional to the concentration of target sequence in the reaction (5). The signal for the first 3-10 cycles of the "no template" control (NTC) sample is designated as the baseline. The presence of the NTC signal as a line near zero indicates that no increase in background signal occurs over the course of the reaction, resulting in maximum sensitivity. The human GAPDH expression analysis kit specifically detects GAPDH mRNA sequences and not genomic DNA or pseudogene sequences (3). This kit can detect the human GAPDH mRNA target within 1 pg total RNA or 0.01 pg poly(A)+ RNA (6). Using the Absolutely RNA microprep kit, GAPDH mRNA was readily detected from RNA samples isolated from the equivalent of one cell, with $\mathrm{C}_{t}$ values of 35 for HeLa and 36 for THP- 1 cells. No signal was generated from the NTC sample (Figure 3). As expected, a consistent increase of $\mathrm{C}_{t}$ value was observed with decreasing cell numbers.

\section{DISCUSSION}

In this report, we demonstrate the suitability of the Absolutely RNA microprep kit for isolating RNA from small samples of cultured cells and LCM samples. The method generates pure intact RNA with ample yields for applications such as RT-PCR and gel electrophoresis.

Conventional RT-PCR is commonly used to detect the presence or absence of a particular RNA sequence, whereas real-time RT-PCR can measure the amount of a specific RNA with great sensitivity. Conventional RT-PCR was used for the detection of various RNAs in two regions of a brain tumor sample. Real-time RT-PCR was used to detect GAPDH RNA from the equivalent of one cell from two different cell lines. Considering that a typical cell contains approximately $10 \mathrm{pg}$ RNA (7), these results show a high degree of sensitivity, reflecting the efficient recovery of pure RNA.

LCM is an effective method for harvesting individual cells from tissue sections. The method facilitates separation and isolation of adjacent cells within a tissue, thereby facilitating analysis of cellular components such as RNA. Because of the small size of these samples, efficient recovery of pure RNA is essential. Efficient RNA recovery was demonstrated by successful amplification using conventional RT-PCR of the RNA from as few as five cells and using molecular beacon quantitative RT-PCR from the equivalent of one cell. In addition, RNA isolated from malignant glioma cells using the Absolutely RNA microprep kit has been used in differential display experiments. These experiments identified several differentially expressed genes in the invasive rim of the tumor relative to the noninvasive tumor core (M. Berens, personal communication) (2).

Use of the Absolutely RNA microprep kit in conjunction with techniques such as LCM and RT-PCR provides the means for gene expression analysis of individual cells within a tissue. Furthermore, the use of such samples for microarray analysis will facilitate the generation of gene expression profiles for each distinguishable cell type within a tissue.

\section{ACKNOWLEDGMENTS}

The authors thank M. Berens, Neurology Research, Barrow Neurological Institute, Phoenix, AZ, for LCM samples, R. Saiz and R. Mueller for help with molecular beacon RTPCR, and J.C. Reed for manuscript review.

\section{REFERENCES}

1.Adams, M.D., A.R. Kerlavage, R.D. Fleischmann, R.A. Fuldner, C.J. Bult, N.H. Lee, E.F. Kirkness, K.G. Weinstock, J.D. Gocayne, O. White et al. 1995. Initial assessment of human gene diversity and expression patterns based upon 83 million nucleotides of cDNA sequence. Nature 377:3-174.

2.Berens, M.E., W.S. McDonough, D.B. Hoelzinger, E. Kaczmarek, A. Giese, and S.W. Coons. 2000. Diverse mechanisms of glioma migration and invasion revealed by mRNA differential display. Proc. Am. Assoc. Cancer Res. 41:232.

3.Cayouette, M., L. Grismer, A. Sucharczuk, and J. Moores. 1999. New endogenous control kits for RT-PCR-based quantitative gene expression analysis. Strategies 12:89-92.

4.Emmert-Buck, M.R., R.F. Bonner, P.D. Smith, R.F. Chuaqui, Z. Zhuang, S.R. Goldstein, R.A. Weiss, and L.A. Liotta. 1996. Laser capture microdissection. Science 274:998-1001.

5.Higuchi, R., C. Fockler, G. Dollinger, and R. Watson. 1993. Kinetic PCR analysis: real-time monitoring of DNA amplification reactions. BioTechnology 11:1026-1030.

6.Padmabandu, G. and R. Mueller. 1999. Quantify gene expression using molecular beacons. Strategies 11:94-97.

7.Sambrook, J., E.F. Fritsch, and T. Maniatis. 1989. Molecular Cloning: A Laboratory Manual, 2nd ed. CSH Laboratory Press, Cold Spring Harbor, NY.

8.Tyagi, S. and F.R. Kramer. 1996. Molecular beacons: probes that fluoresce upon hybridization. Nat. Biotechnol. 14:303-308.

Address correspondence to Dr. Jeff Braman, Stratagene, 11011 N. Torrey Pines Rd., La Jolla, CA 92037, USA, e-mail: jeff_braman@stratagene.com 